Check for updates

Cite this: RSC Adv., 2019, 9, 16130

\title{
High proton conductivity behavior in a 2D metal sulfite constructed from a histidine ligand $\dagger$
}

\author{
Yike $\mathrm{Ma},{ }^{a}$ Liangliang Huang, (D) *a Zhijia Xiu, ${ }^{a}$ Yuheng Yang, ${ }^{a}$ Xiaodong Wang, ${ }^{a}$ \\ Yanzhen Yin, ${ }^{* c}$ Yanfeng Bi (DD ${ }^{* a}$ and Zhiping Zheng ${ }^{\mathrm{ab}}$
}

In the presence of the amino acid histidine, an inorganic-organic hybrid metal sulfite, $\mathrm{Zn}_{2}\left(\mathrm{SO}_{3}\right)_{2}\left(\mathrm{C}_{6} \mathrm{~N}_{3} \mathrm{O}_{2} \mathrm{H}_{9}\right)_{2} \cdot \mathrm{H}_{2} \mathrm{O}$ (1), has been prepared under hydrothermal conditions. Single-crystal $\mathrm{X}$-ray diffraction analysis reveals that 1 shows a 2D layer framework built up from a classical second building unit (S4R), and bridged histidine molecule. Notably, it is the first report of a metal sulfite in the presence of an amino acid molecule. A $1 \mathrm{D} \mathrm{H}$-bonding array can be constructed by the $\mathrm{H}$-bonding interaction between histidine molecules and sulfite groups. Moreover, a new function of metal sulfite for proton conduction was investigated by alternating-current impedance analysis. The results demonstrate that compound 1 shows a high proton conductivity of approximately $10^{-3} \mathrm{~S} \mathrm{~cm}^{-1}$ at $348 \mathrm{~K}$ and $98 \%$ relative humidity.

Received 2nd March 2019

Accepted 22nd April 2019

DOI: 10.1039/c9ra01584a

rsc.li/rsc-advances

framework materials based on oxyanions, such as phosphates, ${ }^{12,13}$ phosphites, ${ }^{14-16}$ and sulfates, ${ }^{17,18}$ exhibit well-defined pore architectures and variable framework compositions. On the one hand, proton carriers (e.g., $\mathrm{H}_{3} \mathrm{O}^{+}, \mathrm{NH}_{4}{ }^{+}$, imidazole, $\mathrm{H}_{2} \mathrm{O}$ and $-\mathrm{COOH}$ ) can be easily introduced into their free voids or in their frameworks, which is an effective approach to prepare high performance proton-conducting materials. ${ }^{19-22}$ On the other hand, the hydrogen bond networks between host-guest or guest-guest can provide proton-conducting pathways. ${ }^{23-27}$ In addition, high hydrothermal stability which is very important for proton-conducting materials in fuel cells is usually another significant feature of these materials. ${ }^{24,28}$ Current endeavors on the study of proton-conducting materials have demonstrated that metal phosphates, phosphites and sulfates show proton conduction. ${ }^{29-35}$ For example, $\left[\left\{\operatorname{In}_{2}(\mu-\mathrm{OH})_{2}\left(\mathrm{SO}_{4}\right)_{4}\right\} \cdot\left\{(\mathrm{LH})_{4}\right\}\right.$. $\left.n \mathrm{H}_{2} \mathrm{O}\right]_{n}(\mathrm{LH}=$ protonated melamine $)$ carries a continuous water array functioning as a solid-state proton conductor $(\sigma=4.4 \times$ $10^{-5} \mathrm{~S} \mathrm{~cm}^{-1}, 98 \% \mathrm{RH}$, and $T=303.15 \mathrm{~K}$ ), a three-dimensional beryllium phosphate with intersecting 24-membered ring channels displays exceptional hydrothermal stability and shows a high proton conductivity on the order of $10^{-3} \mathrm{~S} \mathrm{~cm}^{-1}$ at $25^{\circ} \mathrm{C}$ under high humidity conditions. ${ }^{34,35}$

We are particularly interested in the use of 3-connected centers as basic structural units for the construction of inorganic open-framework materials, such as a chiral indium phosphite with intertwined host and guest helices and a layered cobalt phosphite-oxalate with proton conductivity. ${ }^{36,37}$ In order to expand the field of research concerning inorganic openframework materials with 3-connected centers as basic structural units, we try to introduce sulfite into the inorganic framework. However, because of the instability of $\mathrm{S}$ in its +4 oxidation state, sulfates are usually obtained as products in 
most of the reactions even when $\mathrm{SO}_{3}{ }^{2-}$ is used as the $\mathrm{S}$ source. Probably due to this difficulty, there are few open-framework metal sulfites known..$^{38-40}$ Herein, we use histidine as the organic template to synthesize a metal sulfite. Histidine molecules have a variety of coordination modes, and each functional group can be bonded to a metal center, wherein carboxylic acid is often introduced as a functional group capable of improving proton conduction properties in a proton conductive material, and a side chain imidazole is a common ligand in metal inorganic-organic hybrid materials, these functional groups can enhance proton conduction efficiency in theory. ${ }^{8-11}$

In this paper, a 2D layered zinc sulfite $\mathrm{Zn}_{2}\left(\mathrm{SO}_{3}\right)_{2}(-$ $\left.\mathrm{C}_{6} \mathrm{~N}_{3} \mathrm{O}_{2} \mathrm{H}_{9}\right)_{2} \cdot \mathrm{H}_{2} \mathrm{O}$ with a histidine molecule as the ligand has been hydrothermally synthesized, which is the first report of a metal sulfite in the presence of an amino acid molecule. Notably, this compound shows a high proton conductivity in the order of $10^{-3} \mathrm{~S} \mathrm{~cm}^{-1}$ at $348 \mathrm{~K}$ and $98 \% \mathrm{RH}$.

\section{Experimental section}

\section{Materials and instrumentation}

All chemical samples were obtained from commercial sources and used without further purification. The X-ray diffraction (XRD) pattern was obtained with a Bruker D8 Advance diffractometer with $\mathrm{Cu}-\mathrm{K} \alpha(\lambda=1.5418 \AA, 40 \mathrm{kV}, 40 \mathrm{~mA})$ radiation in the scan range of $4-40^{\circ}$ with a step size of $0.02^{\circ}$. The elemental analysis was conducted on a Vario EL cube elemental analyzer. ICP-AES (inductively coupled plasma-atomic emission spectroscope) analysis was performed on a PerkinElmer Optima 3300DV ICP instrument. FT-IR spectra was recorded on a Nicolet Impact 410 spectrometer between 400 and $4000 \mathrm{~cm}^{-1}$ using the $\mathrm{KBr}$ pellet method. Thermogravimetric analysis (TGA) was conducted on a PerkinElmer TGA 7 thermogravimetric analyzer at a ramp rate of $10{ }^{\circ} \mathrm{C} \mathrm{min}^{-1}$ under a flow of air gas from room temperature to $800{ }^{\circ} \mathrm{C}$. Photoluminescence analyses were performed on an Edinburgh Instrument FLS920 luminescence spectrometer.

\section{Synthesis}

The zinc sulfite compound, $\mathrm{Zn}_{2}\left(\mathrm{SO}_{3}\right)_{2}\left(\mathrm{C}_{6} \mathrm{~N}_{3} \mathrm{O}_{2} \mathrm{H}_{9}\right)_{2} \cdot \mathrm{H}_{2} \mathrm{O}$, was synthesized from $\mathrm{Zn}(\mathrm{Ac})_{2} \cdot 4 \mathrm{H}_{2} \mathrm{O}, \mathrm{NaHSO}_{3}$, and L-histidine in a $\mathrm{H}_{2} \mathrm{O}$ solution. A mixture of $0.1 \mathrm{~g} \mathrm{Zn}(\mathrm{Ac})_{2} \cdot 4 \mathrm{H}_{2} \mathrm{O}, 0.4 \mathrm{~g}$ sodium hydrogen sulfite $\left(\mathrm{NaHSO}_{3}\right)$, and $0.2 \mathrm{~g}$ L-histidine was dissolved in $2.0 \mathrm{~mL}$ of water. The mixture was further stirred for 30 minutes at room temperature and heated at $115^{\circ} \mathrm{C}$ for 5 days in a $23 \mathrm{ml}$ Teflon-lined stainless steel autoclave (filled up to $27 \%$ volume capacity), followed by slow cooling down to the ambient temperature. Colorless crystals could be achieved, washed with water, then filtered, and dried in air. The yield of the product was $56 \%$ in weight based on zinc. The experimental XRD pattern are in good agreement with the simulated ones from the single-crystal X-ray diffraction (Fig. S1 $\dagger$ ). Analysis found (wt\%): Zn, 21.07; S, 10.25; C, 23.16; H, 3.18; N, 13.65; calcd (wt\%): Zn, 21.12; S, 10.36; C, 23.27; H, 3.26; N, 13.57. IR data $\left(\mathrm{KBr}, \mathrm{cm}^{-1}\right)$ : $3133 \mathrm{~m}, 3037 \mathrm{~m}, 2910 \mathrm{~m}, 1644 \mathrm{~s}, 1585 \mathrm{~s}, 1409 \mathrm{~m}, 1367 \mathrm{w}, 1292 \mathrm{w}$, 1267 w, 1230 w, 1145 w, 1101 w, 1037 w, 937 s, 900 m, 838 w, 817 w, $784 \mathrm{w}, 721 \mathrm{w}, 692 \mathrm{~m}, 632 \mathrm{~m}, 547 \mathrm{w}, 507 \mathrm{~m}, 440 \mathrm{w}$.

\section{Determination of crystal structure}

A suitable single crystal with dimensions of $0.20 \times 0.21 \times 0.22$ $\mathrm{mm}^{3}$ of compound $\mathbf{1}$ was carefully selected under an optical microscope for single crystal XRD analysis. Single-crystal structure determination by X-ray diffraction was performed on a Bruker D8 Quest diffractometer with graphitemonochromated Mo-K $\alpha(\lambda=0.71073 \AA)$ radiation at a temperature of $296 \mathrm{~K}$. Data processing was accomplished with the saint-processing program. The structure was solved by a direct method using the SHELXTL-2014 crystallographic software package. ${ }^{41,42}$ The zinc and sulphur atoms were first located, whereas the carbon, nitrogen and oxygen atoms were found in the different Fourier maps. All the hydrogen atoms were placed geometrically and refined in a riding model. All of the nonhydrogen atoms were refined anisotropically.

The detailed crystallographic data and selected bond lengths as well as the bond angles for compound $\mathbf{1}$ are listed in Table 1 and S1. $\dagger$ CCDC-1892957 contains the supplementary crystallographic data for this paper.

\section{Proton conductivity measurement}

The hydrated proton conductivities of the compound pellets were measured using a CHI660E electrochemical work station. The alternating current frequencies ranged from $1 \mathrm{~Hz}$ to $10^{6} \mathrm{~Hz}$. Variable impedance spectra were collected at different humidity and temperatures. The humidity was controlled by different saturated aqueous salt solutions, which were salt solutions of $\mathrm{Na}_{2} \mathrm{HPO}_{4}(98 \% \mathrm{RH}), \mathrm{NaCl}(76 \% \mathrm{RH}), \mathrm{NaBr}(58 \% \mathrm{RH})$ and $\mathrm{K}_{2} \mathrm{CO}_{3}$ $(44 \% \mathrm{RH})$. The conductivity measurement was performed after setting the sample at different humidities for approximately 48 hours. The proton conductivity $\left(\mathrm{S} \mathrm{cm}^{-1}\right)$ was calculated using the formula $\sigma=L / A R$, where $L$ is the pellet thickness, $A$ is the pellet area (7 $\mathrm{mm}$ in diameter and $0.8 \mathrm{~mm}$ in thickness), and $R$ is the compound impedance obtained from the Nyquist plot.

Table 1 Crystal data and structure refinement for compound 1

\begin{tabular}{|c|c|}
\hline Empirical formula & $\mathrm{C}_{12} \mathrm{H}_{20} \mathrm{~N}_{6} \mathrm{O}_{11} \mathrm{~S}_{2} \mathrm{Zn}_{2}$ \\
\hline Formula weight & 619.26 \\
\hline Temperature/K & 296(2) \\
\hline Crystal system & Monoclinic \\
\hline Space group & $C 2 / c$ \\
\hline$a / \AA$ & $14.6764(7)$ \\
\hline$b / \AA$ & $8.3407(4)$ \\
\hline$c / \AA$ & $16.8021(8)$ \\
\hline$\beta /^{\circ}$ & $101.397(2)$ \\
\hline$V / \AA^{3}$ & $2016.21(17)$ \\
\hline$Z$ & 4 \\
\hline Calculated density $/ \mathrm{g} \mathrm{cm}^{-3}$ & 2.040 \\
\hline Absorption coefficient $/ \mathrm{mm}^{-1}$ & 2.660 \\
\hline$F(000)$ & 1256 \\
\hline Theta range for data collection ${ }^{\circ}$ & 2.5 to 25.1 \\
\hline Refinement method/unique & $8485 / 1782[R($ int $)=0.034]$ \\
\hline Refinement method & Full-matrix least-squares on $F^{2}$ \\
\hline Data/restraints/parameters & $1782 / 0 / 151$ \\
\hline Goodness-of-fit on $F^{2}$ & 1.05 \\
\hline Final $R$ indices $[I>2 \operatorname{sigma}(I)]$ & $R_{1}=0.0258, \mathrm{w} R_{2}=0.0574$ \\
\hline$R$ indices (all data) & $R_{1}=0.0350, \mathrm{w} R_{2}=0.0608$ \\
\hline Largest diff. peak and hole/(e $\left.\AA^{-3}\right)$ & 0.32 and -0.28 \\
\hline
\end{tabular}


The $E_{\mathrm{a}}$ value was derived from the Arrhenius equation: $T \sigma=$ $\sigma_{0} \exp \left(-E_{\mathrm{a}} / k T\right)$, where $\sigma_{0}$ is a pre-exponential factor, $E_{\mathrm{a}}$ is the activation energy, and $k$ is the Boltzmann constant.

\section{Results and discussion}

\section{Structural description}

The single crystal X-ray analysis reveals that $\mathbf{1}$ crystallizes in the monoclinic crystal system with the $C 2 / c$ space group. The asymmetric unit contains one $\mathrm{Zn}$ atom, one $\mathrm{S}$ atom, one L-histidine cation and one free lattice water molecule (Fig. S3†). The crystallographically independent $\mathrm{Zn}$ atom is tetrahedrally coordinated to two $\mathrm{O}$ atoms bridging to the neighboring $\mathrm{S}$ atoms, one carboxyl $\mathrm{O}$ atom and one $\mathrm{N}$ atom from the imidazole of the $\mathrm{L}^{-}$ histidine cations. The $\mathrm{Zn}-\mathrm{O}$ bond lengths are in the range of 1.9247(18)-1.9853(19) $\AA$ and the O-Zn-O bond angles vary in the range of $102.49(8)-112.68(8)^{\circ}$. The $\mathrm{Zn}-\mathrm{N}$ bond length is $1.989(2)$ $\AA$. The crystallographically independent $S$ atom is threecoordinated to oxygen atoms and shares two oxygen atoms with adjacent $\mathrm{Zn}$ atoms, with the third trigonal pyramidal vertex occupied by an terminal oxygen atom $[d(\mathrm{~S}=\mathrm{O})=1.5167(18) \AA]$. The S-O bridging bond lengths are in the range of 1.5167(18)$1.5362(19) \AA$ and the average $\mathrm{O}-\mathrm{S}-\mathrm{O}$ bond angle is $104.83^{\circ}$.

As shown in Fig. 1a, the framework of $\mathrm{Zn}_{2}\left(\mathrm{SO}_{3}\right)_{2}(-$ $\left.\mathrm{C}_{6} \mathrm{~N}_{3} \mathrm{O}_{2} \mathrm{H}_{9}\right)_{2} \cdot \mathrm{H}_{2} \mathrm{O}$ shows a $2 \mathrm{D}$ layered structure, which is built up from a second building unit, namely a single four-membered ring (S4R) and a histidine molecule. The $\mathrm{S} 4 \mathrm{R},\left(\mathrm{ZnSO}_{3}\right)_{2}$, is formed from two tetrahedral $\mathrm{Zn}^{2+}$ cations and two $\mathrm{SO}_{3}{ }^{2-}$ sulfite anions. The histidine molecule is neutral zwitterionic and serves as a bidentate ligand connecting with the adjacent two S4Rs to form a 2D inorganic-organic hybrid layer. In the layer, six $\mathrm{Zn}$ (II) ions, two sulfites and four histidine molecules get together and form a 12-membered ring window.
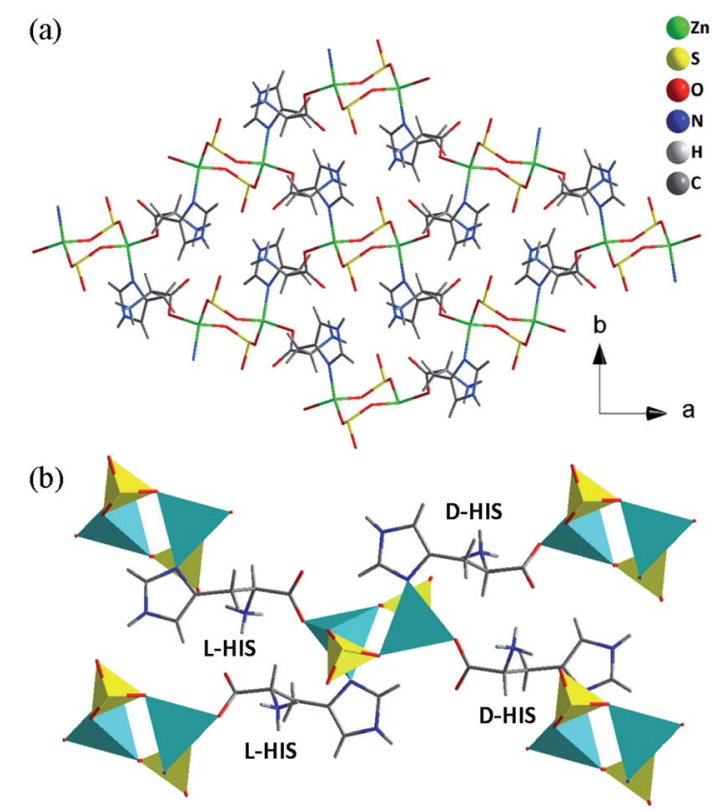

Fig. 1 The structure of compound 1: (a) the 2D layer with the 12membered ring window. (b) The connection between histidine molecules and S4Rs (HIS: histidine).
As shown in Fig. 1b, each S4R is surrounded by two pairs of histidine molecules while each histidine molecule is connected with the adjacent two S4Rs. It is noteworthy that the histidine molecules surrounding the S4R show two different absolute configurations. A pair of histidine molecules on one side of the S4R has the $R$ absolute configuration while the other pair of those on the other side of the S4R has the $S$ absolute configuration. As a result, compound $\mathbf{1}$ is achiral, although the initially added histidine is homochiral. It is demonstrated that the racemization happened in the hydrothermal synthetic system. A similar phenomenon was observed in the synthesis of $\mathrm{Zn}\left(\mathrm{HPO}_{4}\right)\left(\mathrm{C}_{6} \mathrm{H}_{9} \mathrm{~N}_{3} \mathrm{O}_{2}\right), \quad \mathrm{Zn}\left(\mathrm{HPO}_{3}\right)\left(\mathrm{DL}_{-}-\mathrm{C}_{6} \mathrm{H}_{9} \mathrm{~N}_{3} \mathrm{O}_{2}\right)\left(\mathrm{H}_{2} \mathrm{O}\right)_{0.5}$ and ZnPO-CJ36. ${ }^{43-45}$ In order to contrast experiment results, we used D,L-histidine and $\mathrm{D}$-histidine to replace the L-histidine in the system of reaction, but the final structure is not charged and it is still compound 1 . The result further demonstrated that a single chiral histidine does not easily exist in the final structure under hydrothermal synthesis.

As shown in Fig. 2, the $2 \mathrm{D}$ layers are stacked in an $\mathrm{ABAB}$ sequence along the $a$ axis. The lattice water molecules are situated in between the layers, which are held via extensive $\mathrm{O}(\mathrm{W})-$ $\mathrm{H} \cdots \mathrm{O}$ hydrogen bonding interactions between guest molecules and the host framework. The $\mathrm{O} \cdots \mathrm{O}$ distance is $2.83 \AA$. The $\mathrm{H}$ bond provides extra stability to the lattice water molecules, which has been confirmed by the TGA of the powder sample of compound 1 showing a continuous initial loss. ${ }^{34}$ Extensive hydrogen bonds are also formed between the histidine molecules and sulfite units. The $\mathrm{N}(2) \mathrm{H}_{3}{ }^{-}$group forms three hydrogen bonds to one terminal $\mathrm{C}=\mathrm{O}$ group $\left(d_{\mathrm{N} \cdots \mathrm{O}}=2.848(3)\right.$ $\AA)$, two terminal oxygen atoms from sulfite units with an average $\mathrm{N} \cdots \mathrm{O}$ distance of $2.82 \AA$. The $\mathrm{N}(3) \mathrm{H}^{-}$groups of the imidazole moiety form one hydrogen bond with the terminal $\mathrm{O}(3)$ atom from the sulfite unit with a distance of 2.791(3) $\AA$. In addition, there are three types of weak $\mathrm{C}-\mathrm{H} \cdots \mathrm{O}$ hydrogen-bonding interactions: the interaction between the chiral tertiary carbon $\mathrm{C}(2)$ atom and the $\mu_{2}-\mathrm{O}(4)$ of the carboxyl oxygen atoms, the interaction between the $\mathrm{C}(5)$ atom from imidazole and the terminal $\mathrm{O}(5)$ of the carboxyl oxygen atoms, and the interaction between the $\mathrm{C}(6)$ atom from imidazole and $\mu_{2}-\mathrm{O}(2)$ of the sulfite group. Because of the $\mathrm{H}$-bond interactions between the histidine molecules and sulfite groups, a 1D H-bonding array can be constructed (Fig. S4†). Finally, the hydrogen bonding interactions among water molecules, histidine molecules and sulfite

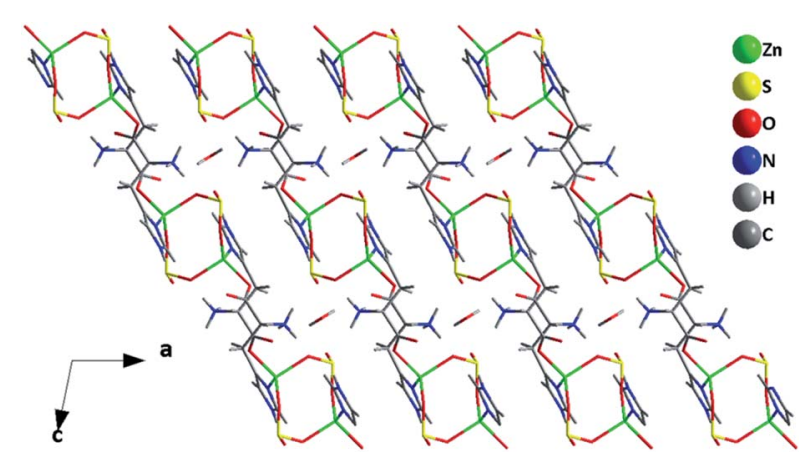

Fig. 2 The 2D layers are stacked in an ABAB sequence along the $a$ axis. 
units construct a pseudo-3D supramolecular structure (Fig. 3). The detailed H-bond data is listed in Table S2. $\dagger$

As far as we know, compound $\mathbf{1}$ is the first zinc sulfite to be prepared in the presence of a histidine molecule. The histidine acts as a bridge between inorganic secondary building blocks which directly cross-link to the framework. In the past, although some zinc sulfite frameworks are already reported such as $\left(\mathrm{NH}_{3} \mathrm{CH}_{2} \mathrm{CH}_{2} \mathrm{NH}_{3}\right)\left[\mathrm{Zn}_{3}\left(\mathrm{SO}_{3}\right)_{4}\right],{ }^{40}$ the structure of cross-linking organic metal-sulfites has been rarely reported.

\section{Proton conductivity}

In the structure of $\mathrm{Zn}_{2}\left(\mathrm{SO}_{3}\right)_{2}\left(\mathrm{C}_{6} \mathrm{~N}_{3} \mathrm{O}_{2} \mathrm{H}_{9}\right) \cdot \mathrm{H}_{2} \mathrm{O}$, there are water molecules and a 1D H-bonding array. Therefore, compound $\mathbf{1}$ is expected to conduct protons and proton conduction behavior was investigated by AC impedance measurement both as a function of temperature at constant $\mathrm{RH}$ and as a function of $\mathrm{RH}$ at constant temperature. The proton conductivity was estimated from the Nyquist plots shown in Fig. 4, 5 and S5-S7. $\dagger$ The proton conductivity of different relative humidity (RH) at $303 \mathrm{~K}$ was measured. It was demonstrated that the proton conductivity increases with the increase of humidity (Fig. 4). This phenomenon is well proven at low temperatures, the proton conductivity is $2.05 \times 10^{-9} \mathrm{~S} \mathrm{~cm}^{-1}$ under $44 \% \mathrm{RH}$ and reaches $1.01 \times 10^{-5} \mathrm{~S} \mathrm{~cm}^{-1}$ under $98 \% \mathrm{RH}$. Even though the proton conductivity of $\mathbf{1}$ was not remarkable at room temperature and $98 \% \mathrm{RH}$, it is comparable to several materials such as [ $\mathrm{Zn}\left(\mathrm{D}^{-}\right.$ $\mathrm{LCl})(\mathrm{Cl})]\left(\mathrm{H}_{2} \mathrm{O}\right)_{2}\left(4.42 \times 10^{-5} \mathrm{~S} \mathrm{~cm}^{-1}\right.$ at $\left.304 \mathrm{~K}, 98 \% \mathrm{RH}\right),\left[\mathrm{H}_{3} \mathrm{O}\right]$ $\left[\mathrm{Ni}\left(\mathrm{SO}_{4}\right) \mathrm{F}\right]\left(7.9 \times 10^{-6} \mathrm{~S} \mathrm{~cm}^{-1}\right.$ at $\left.298 \mathrm{~K}, 98 \% \mathrm{RH}\right)$ and

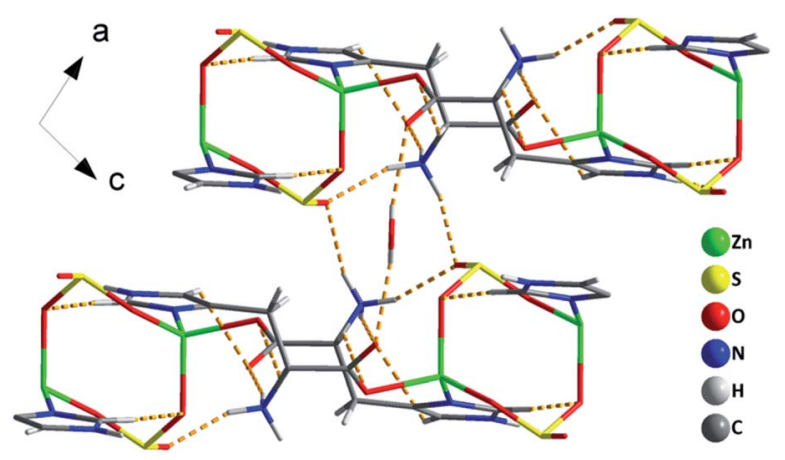

Fig. 3 View of $\mathrm{H}$-bonding interactions existing in the structure of 1.

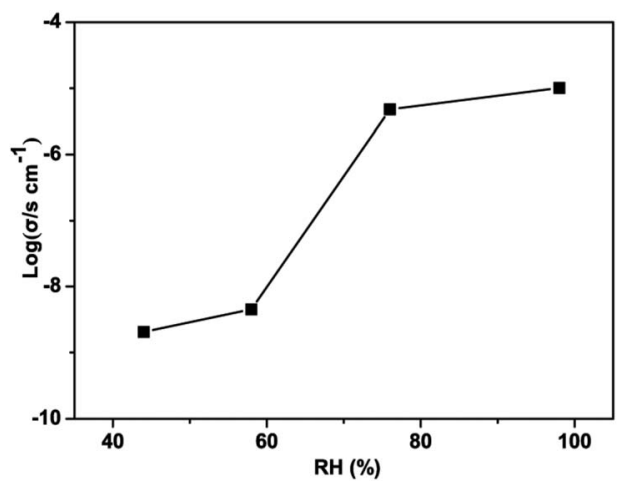

Fig. 4 Humidity dependence of the proton conductivity at $303 \mathrm{~K}$.
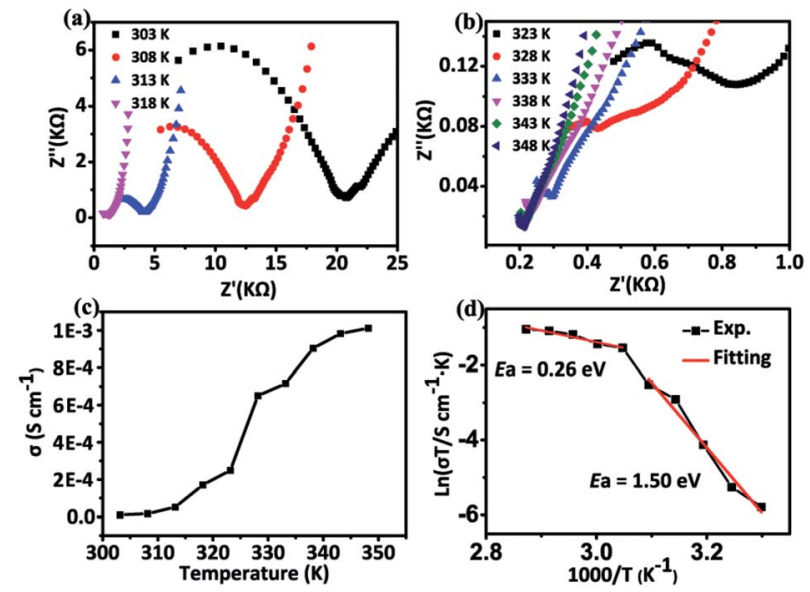

Fig. 5 (a) and (b) Nyquist plots of 1 at various temperatures under $98 \%$ $\mathrm{RH}$. (c) Temperature dependence of the proton conductivity of 1 . (d) Arrhenius plot of 1 .

$\left[\left\{\mathrm{In}_{2}(\mathrm{OH})_{2}\left(\mathrm{SO}_{4}\right)_{4}\right\} \cdot\left\{(\mathrm{LH})_{4}\right\} \cdot n \mathrm{H}_{2} \mathrm{O}\right]_{n}\left(4.4 \times 10^{-5} \mathrm{~S} \mathrm{~cm}^{-1}\right.$ at $303 \mathrm{~K}$, 98\% RH). ${ }^{34,46}$ As shown in Fig. S5-S7, $\dagger$ we found that at high temperature under humid conditions, the semicircle of the Nyquist plot basically disappears, which is similar to the phenomenon reported previously in the literature. ${ }^{47-49}$

To gain insight into the proton-conduction mechanism, we calculated the activation energy at different temperatures under $98 \% \mathrm{RH}$ (Fig. 5). It is obvious that the resistance of the compound decreases with increasing temperature, indicating a sustained increase in proton conductivity. The proton conductivity increased from $1.01 \times 10^{-5} \mathrm{~S} \mathrm{~cm}^{-1}$ at $303 \mathrm{~K}$ to 2.49 $\times 10^{-4} \mathrm{~S} \mathrm{~cm}^{-1}$ at $323 \mathrm{~K}$. It is worth noting that the conductivity has a jump in growth around $323 \mathrm{~K}$, and a maximum value is reached $1.01 \times 10^{-3} \mathrm{~S} \mathrm{~cm}^{-1}$ at $348 \mathrm{~K}$. This value was comparable to some MOFs such as $\left[\mathrm{LnL}\left(\mathrm{H}_{2} \mathrm{O}\right)_{3}\right] \cdot 2 \mathrm{H}_{2} \mathrm{O}(\mathrm{L}=N$-phenyl$N^{\prime}$-phenylbicyclo-[2,2,2]-oct-7-ene-2,3,5,6-tetra-carboxdiimide tetracarboxylic acid, $\mathrm{Ln}=\mathrm{Eu}, \mathrm{Dy})\left(10^{-5} \mathrm{~S} \mathrm{~cm}^{-1}, 343 \mathrm{~K}, 97 \% \mathrm{RH}\right)$, POMs such as NENU-530 $\left(10^{-3} \mathrm{~S} \mathrm{~cm}^{-1}, 343 \mathrm{~K}, 98 \% \mathrm{RH}\right)$, metal phosphates such as $\left(\mathrm{NH}_{4}\right)_{2} \mathrm{Al}_{4}\left(\mathrm{PO}_{4}\right)_{4}\left(\mathrm{HPO}_{4}\right) \cdot \mathrm{H}_{2} \mathrm{O}\left(10^{-4} \mathrm{~S} \mathrm{~cm}^{-1}\right.$, $343 \mathrm{~K}, 99 \% \mathrm{RH})$ and metal phosphites, like $\left(\mathrm{NH}_{4}\right)_{0.59}(-$ $\left.\mathrm{H}_{3} \mathrm{O}\right)_{1.41} \mathrm{Mn}_{5}\left(\mathrm{HPO}_{3}\right)_{6}\left(10^{-4} \mathrm{~S} \mathrm{~cm}^{-1}, 328 \mathrm{~K}, 98 \% \mathrm{RH}\right) .{ }^{47-55}$ By linearly fitting the relationship between $\ln (\sigma T)$ and $1000 / T$, the activation energy of proton transport is estimated to be $1.50 \mathrm{eV}$ at $98 \% \mathrm{RH}$ between $303 \mathrm{~K}$ and $323 \mathrm{~K}$ while the $E_{\mathrm{a}}$ is $0.26 \mathrm{eV}$ between $328 \mathrm{~K}$ to $348 \mathrm{~K}$ (Fig. $5 \mathrm{~d}$ ). Therefore, the above results suggest that the vehicle mechanism and the Grotthuss mechanism should exist in the temperature range of 303-348 K according to the value of $E_{\mathrm{a}}$ (vehicle mechanism: $E_{\mathrm{a}}>0.4 \mathrm{eV}$; Grotthuss mechanism: $\left.E_{\mathrm{a}}<0.4 \mathrm{eV}\right) .{ }^{2,56}$ The proton conduction pathway could be further understood by analyzing the structure of the compound and the $E_{\mathrm{a}}$ value. As shown in Fig. S4, $\dagger$ a $1 \mathrm{D} \mathrm{H}-$ bonding array can be constructed because of the H-bond interactions between histidine molecules and sulfite groups, which should be active in promoting a Grotthuss type conduction. In the temperature range of $328-348 \mathrm{~K}$, the $E_{\mathrm{a}}$ was measured to be $0.26 \mathrm{eV}$, which is quite a low value suggesting probably the Grotthuss mechanism. However, the activation energy of compound $\mathbf{1}$ is higher at low temperatures (303-323 


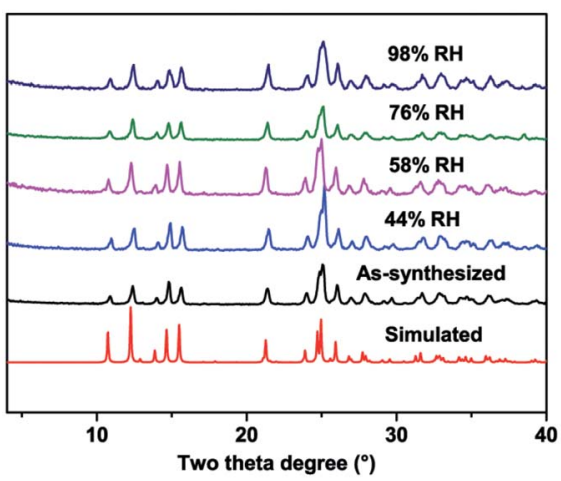

Fig. 6 PXRD patterns of simulated, as-synthesized, and after impedance test under different humidity phases of compound 1.

$\mathrm{K})$, the $E_{\mathrm{a}}$ is estimated to be $1.50 \mathrm{eV}$, showing that the proton transport process follows the vehicle mechanism, proton conduction may be due to the diffusion or transfer of crystalline water molecules between layers, which requires a higher activation energy. ${ }^{2}$ A similar phenomenon has been reported in a lanthanide carbonate cluster based MOF with the formula $\left\{\left[\mathrm{Gd}_{2}\left(\mathrm{CO}_{3}\right)(\mathrm{ox})_{2}\left(\mathrm{H}_{2} \mathrm{O}\right)_{2}\right] \cdot 3 \mathrm{H}_{2} \mathrm{O}\right\}_{n} \cdot{ }^{57}$

To further investigate the humidity and temperature stability of compound 1, we performed a PXRD test on samples after the electrochemical test under different humidity and temperature conditions. As shown in Fig. 6, the structure of compound 1 did not change even after electrochemical testing under conditions of $348 \mathrm{~K}$ and $98 \% \mathrm{RH}$, indicating that compound 1 has good structural stability, and this property is valuable in practical applications.

\section{TGA analysis}

Thermogravimetric analysis carried out in the air at a heating rate of $10^{\circ} \mathrm{C} \mathrm{min}^{-1}$ up to temperature of $800{ }^{\circ} \mathrm{C}$. The continuous two-step weight loss was observed in the range of $220-673{ }^{\circ} \mathrm{C}$. The total observed weight loss of $71.94 \mathrm{wt} \%$ is attributed to the removal of water molecules (calcd $2.91 \mathrm{wt} \%$ ) and the decomposition of L-histidine (calcd $50.11 \mathrm{wt} \%$ ) and the sulfur dioxide molecule (calcd $20.67 \mathrm{wt} \%$ ) in the framework (Fig. S8 $\dagger$ ).

\section{Photoluminescence spectrum}

The photoluminescence spectra of $\mathbf{1}$ and the histidine molecules were measured in a solid state at room temperature (Fig. S9 $\dagger$ ). The emission spectrum of $\mathrm{Zn}_{2}\left(\mathrm{SO}_{3}\right)_{2}\left(\mathrm{C}_{6} \mathrm{~N}_{3} \mathrm{O}_{2} \mathrm{H}_{9}\right)$ showed a peak at $465 \mathrm{~nm}$ and excited at a wavelength of $407 \mathrm{~nm}$, red-shifted compared to pure L-histidine. The reason is that the coordination between histidine and zinc ions effectively increases the rigidity of the ligand and reduces the energy loss through non-radiative thermal vibration. ${ }^{58-61}$

\section{Conclusions}

In summary, a two-dimensional layered zinc sulfite coordinated by histidine is synthesized under hydrothermal conditions. Notably, an amino acid is firstly introduced into the family of metal sulfites. Proton conductivity investigations on the title compound have been carried out and the proton transmission rate was estimated to be $10^{-3} \mathrm{~S} \mathrm{~cm}^{-1}$ at $348 \mathrm{~K}$ and $98 \%$ humidity. Additionally, the vehicle and Grotthuss proton conduction mechanisms are realized at 303-323 $\mathrm{K}$ and 328-348 $\mathrm{K}$, respectively, which can be attributed to the transfer of crystalline water molecules and the 1D H-bonding array in the framework. Our investigation further exemplifies the possibility of constructing a metal sulfite with biofunctional molecules and exploring a new proton-conducting material in metal sulfite systems. Further work on the syntheses of such metal sulfite analogues for proton conduction is in progress.

\section{Conflicts of interest}

There are no conflicts to declare.

\section{Acknowledgements}

We thank National Natural Science Foundation of China (No. 21201095, 51663020 and 21301170), Educational Bureau of Liaoning Province for the Fundamental Research of Key Lab (No. L2017LZD002) and the National Science Fund for Distinguished Young Scholars of Guangxi Province (No. 2017JJG150011) for financial support.

\section{References}

1 J. A. Hurd, R. Vaidhyanathan, V. Thangadurai, C. I. Ratcliffe, I. L. Moudrakovski and G. K. Shimizu, Nat. Chem., 2009, 1, 705-710.

2 X. Meng, H.-N. Wang, S.-Y. Song and H.-J. Zhang, Chem. Soc. Rev., 2017, 46, 464-480.

3 X. Guan, Y. Ma, H. Li, Y. Yusran, M. Xue, Q. Fang, Y. Yan, V. Valtchev and S. Qiu, J. Am. Chem. Soc., 2018, 140, 44944498.

4 M. Inukai, S. Horike, T. Itakura, R. Shinozaki, N. Ogiwara, D. Umeyama, S. S. Nagarkar, Y. Nishiyama, M. Malon, A. Hayashi, T. Ohhara, R. Kiyanagi and S. Kitagawa, J. Am. Chem. Soc., 2016, 138, 8505-8511.

5 K. M. Mauritz and R. B. Moore, Chem. Rev., 2004, 104, 45354585.

6 G. Alberti and M. Casciola, Solid State Ionics, 2001, 145, 3-16. 7 F. Yang, G. Xu, Y. Dou, B. Wang, H. Zhang, H. Wu, W. Zhou, J.-R. Li and B. Chen, Nat. Energy, 2017, 2, 877-883.

8 M. Sadakiyo, T. Yamada and H. Kitagawa, ChemPlusChem, 2016, 81, 691-701.

9 A. Shigematsu, T. Yamada and H. Kitagawa, J. Am. Chem. Soc., 2011, 133, 2034-2036.

10 Y. Ye, L. Zhang, Q. Peng, G. Wang, Y. Shen, Z. Li, L. Wang, X. Ma, Q.-H. Chen, Z. Zhang and S. Xiang, J. Am. Chem. Soc., 2015, 137, 913-918.

11 S. Bureekaew, S. Horike, M. Higuchi, M. Mizuno, T. Kawamura, D. Tanaka, N. Yanai and S. Kitagawa, Nat. Mater., 2009, 8, 831-836.

12 T. Su, H. Xing, J. Xu, J. Yu and R. Xu, Inorg. Chem., 2011, 50, 1073-1078. 
13 G.-M. Wang, J.-H. Li, X. Zhang, J.-Q. Jiao, Z.-Z. Bao, X.-M. Zhao, W.-W. Jiang, Y.-X. Wang and J.-H. Lin, Inorg. Chem. Commun., 2014, 46, 295-300.

14 P. Ramaswamy, S. Mandal and S. Natarajan, Inorg. Chim. Acta, 2011, 372, 136-144.

15 K. Wang, Y. Bian, J. Li, D. Xu and Z. Lin, Inorg. Chem., 2016, 55, 3727-3729.

16 Z.-Z. Xue, J. Pan, J.-H. Li, Z.-H. Wang and G.-M. Wang, J. Mol. Struct., 2017, 1138, 1-5.

17 S. R. Marri, S. Mahana, D. Topwal and J. N. Behera, Dalton Trans., 2017, 46, 1105-1111.

18 K. Wang, D. Luo, D. Xu, F. Guo, L. Liu and Z. Lin, Dalton Trans., 2014, 43, 13476-13479.

19 X. Zhao, C. Mao, X. Bu and P. Feng, Chem. Mater., 2014, 26, 2492-2495.

20 S. Horike, D. Umeyama, M. Inukai, T. Itakura and S. Kitagawa, J. Am. Chem. Soc., 2012, 134, 7612-7615.

21 M. Sadakiyo, T. Yamada, K. Honda, H. Matsui and H. Kitagawa, J. Am. Chem. Soc., 2014, 136, 7701-7707.

22 A. Mallick, T. Kundu and R. Banerjee, Chem. Commun., 2012, 48, 8829-8831.

23 T. Kundu, S. C. Sahoo and R. Banerjee, Chem. Commun., 2012, 48, 4998-5000.

24 M. Wei, X. Wang and X. Duan, Chem.-Eur. J., 2013, 19, 16071616.

25 S. S. Nagarkar, S. M. Unni, A. Sharma, S. Kurungot and S. K. Ghosh, Angew. Chem., Int. Ed., 2014, 53, 2638-2642.

26 G.-L. Zheng, G.-C. Yang, S.-Y. Song, X.-Z. Song and H.-J. Zhang, CrystEngComm, 2014, 16, 64-68.

27 M. Bazaga-Garcia, R. M. P. Colodrero, M. Papadaki, P. Garczarek, J. Zon, P. Olivera-Pastor, E. R. Losilla, L. Leon-Reina, M. A. G. Aranda, D. Choquesillo-Lazarte, K. D. Demadis and A. Cabeza, J. Am. Chem. Soc., 2014, 136, 5731-5739.

28 G.-G. Cao, J.-D. Liu, T.-T. Zhuang, X.-H. Cai and S.-T. Zheng, Chem. Commun., 2015, 51, 2048-2051.

29 M. Wang, H.-B. Luo, J. Zhang, S.-X. Liu, C. Xue, Y. Zou and X.-M. Ren, Dalton Trans., 2017, 46, 7904-7910.

30 H.-R. Zhao, C. Xue, C.-P. Li, K. Zhang, H.-B. Luo, S.-X. Liu and X.-M. Ren, Inorg. Chem., 2016, 55, 8971-8975.

31 J. Shi, K. Wang, J. Li, H. Zeng, Q. Zhang and Z. Lin, Dalton Trans., 2018, 47, 654-658.

32 C. Guo, C. Chen, K. Wang, H. Zeng and Z. Lin, Inorg. Chem. Commun., 2017, 85, 96-99.

33 Y. Yu, J. Zhu, J. Liu, Y. Yan and X. Song, Dalton Trans., 2017, 46, 9157-9162.

34 B. Manna, B. Anothumakkool, A. V. Desai, P. Samanta, S. Kurungot and S. K. Ghosh, Inorg. Chem., 2015, 54, 53665371.

35 K. Wang, T. Li, H. Zeng, G. Zou, Q. Zhang and Z. Lin, Inorg. Chem., 2018, 57, 8726-8729.

36 L. Huang, T. Song, Y. Fan, L. Wang, C. Ji, L. Shan and L. Wang, Microporous Mesoporous Mater., 2012, 149, 95-100.

37 F. Gao, L. Huang, Z. Xiu, Y. Yin, Y. Ma, Y. Bi and Z. Zheng, CrystEngComm, 2018, 20, 5544-5550.
38 G. I. Chilas, N. Lalioti and T. Vaimakis, Dalton Trans., 2010, 39, 8296-8305.

39 R. K. Tiwari and J. N. Behera, Dalton Trans., 2017, 46, 59115917.

40 R. K. Tiwari, J. Kumar and J. N. Behera, Chem. Commun., 2016, 52, 1282-1285.

41 G. M. Sheldrick, SHELXTL-NT, Version 5.1, Bruker AXS Inc., Madison, WI, 1997.

42 D. T. Cromer and J. T. Waber, International Tables for X-Ray Crystallography, Kynoch Press, Birmingham, AL, 1974, vol. 4, Table 2.2A.

43 J. Fan, C. Slebodnick, R. Angel and B. E. Hanson, Inorg. Chem., 2005, 44, 552-558.

44 L. Chen and X. Bu, Chem. Mater., 2006, 18, 1857-1860.

45 L. Zhao, J. Li, P. Chen, Z. Dong, J. Yu and R. Xu, CrystEngComm, 2008, 10, 497-501.

46 S. C. Sahoo, T. Kundu and R. Banerjee, J. Am. Chem. Soc., 2011, 133, 17950-17958.

47 X. Xie, S. Yu, C. Yang, J. Zhang, Z. Li and G. Li, New J. Chem., 2018, 42, 20197-20204.

48 D. Umeyama, S. Horike, M. Inukai, Y. Hijikata and S. Kitagawa, Angew. Chem., Int. Ed., 2011, 50, 11706-11709.

49 W. Li, L. X. Xu, D. Luo, H. Wu, J. Tu and M. Yang, Eur. Polym. J., 2007, 43, 522-528.

50 M. Zhu, Z.-M. Hao, X.-Z. Song, X. Meng, S.-N. Zhao, S.-Y. Song and H.-J. Zhang, Chem. Commun., 2014, 50, 1912-1914.

51 J. Li, X.-L. Cao, Y.-Y. Wang, S.-R. Zhang, D.-Y. Du, J.-S. Qin, S.-L. Li, Z.-M. Su and Y.-Q. Lan, Chem.-Eur. J., 2016, 22, 9299-9304.

52 C. Xue, Y. Zou, S.-X. Liu, X.-M. Ren and Z.-F. Tian, J. Solid State Chem., 2018, 258, 695-701.

53 S. D. Mikhailenko, S. Kaliaguine and E. Ghali, Microporous Mater., 1997, 11, 37-44.

54 S. Shalini, S. Aggarwal, S. K. Singh, M. Dutt, T. G. Ajithkumar and R. Vaidhyanathan, Eur. J. Inorg. Chem., 2016, 27, 43824386.

55 S. Shalini, V. M. Dhavale, K. M. Eldho, S. Kurungot, T. G. Ajithkumar and R. Vaidhyanathan, Sci. Rep., 2016, 6, 32489.

56 P. Ramaswamy, N. E. Wong and G. K. H. Shimizu, Chem. Soc. Rev., 2014, 43, 5913-5932.

57 Q. Tang, Y.-L. Yang, N. Zhang, S.-H. Zhang, F.-S. Tang, J.-Y. Hu, Y.-Z. Zheng and F.-P. Liang, Inorg. Chem., 2018, 57, 9020-9027.

58 S. Khatua, A. Santra, S. Padmakumar, K. Tomar and S. Konar, ChemistrySelect, 2018, 3, 785-793.

59 M. D. Allendorf, C. A. Bauer, R. K. Bhakta and R. J. Houk, Chem. Soc. Rev., 2009, 38, 1330-1352.

60 L. Wen, Y. Li, Z. Lu, J. Lin, C. Duan and Q. Meng, Cryst. Growth Des., 2016, 6, 530-537.

61 W. Feng, Y. Xu, G. Zhou, C. Zhang and X. Zheng, Inorg. Chem. Commun., 2007, 10, 49-52. 